\title{
On the Climatic Uncertainty to the Environment Extremes: a Singapore Case and Statistical Approach
}

\author{
Yi Zhang* \\ Division of Infrastructure Systems and Maritime Studies, School of Civil and Environmental Engineering, \\ Nanyang Technological University, Singapore
}

Received: 18 August 2014

Accepted: 2 November 2014

\begin{abstract}
In recent times, increasing economic losses due to unexpected extreme environmental conditions have been noticed. The occurrence of these extreme environmental events requires us to have a clearer understanding of climatic influence on our lives. This paper utilizes the case of Singapore to investigate the influence of climate extremes on a country. The environmental elements of Singapore whose extremes are most likely to change in the future are identified. The impacts of these extremes on an entire nation's economy and public health are discussed. Additionally, climate-induced statistical uncertainties in the modeling of extreme values are investigated. Based on the available knowledge of climate uncertainty information, the change of statistical structure in the extreme value model is discussed. The impact of various types of climate uncertainty in the extreme value modeling for a physical environmental variable is summarized at the end of this paper.
\end{abstract}

Keywords: climate change, extreme value modeling, offshore engineering, Poisson process, uncertainty modeling

\section{Introduction}

It has been widely recognized that climate changes will trigger an increase in extreme environmental events [1]. This is concluded from many discussions on the evidence arguing about whether there is a real influence of climate change on the environment [2]. The occurrences of extreme weather and climate events over the past few decades have been brought to the fore of societal concerns. Both the private sector and governments worry about the apparent increase in the frequency of extreme weather and climate events. These result in negative impact on the environment and human lives.

Great effort has been made to understand the influence of extreme environment events. The importance of climate

*e-mail: zhang_yi87@163.com issues on human land use has been emphasized [3], and the influence of human activities on precipitation also has been shown [4]. Recent articles also have found that agriculture is sensitive to extreme climate conditions [5]. Climatic impact could be particularly amplified in some places which are quite volatile for their high exposure to climate extremes. Typically coastal cities, where a large population may be concentrated, can be vulnerable to climate change impacts such as sea level rise. This, in turn, can adversely affect water resources as a result of flooding, coastal erosion, water scarcity, etc. The importance of these issues have been realized by many countries and cities. Many of the decisions relating to future urban development regarding climate change risks are carefully considered [6].

Singapore is such an example that is particularly vulnerable to climate change as it is an island nation with a 
dense population in one city. Singapore is quite reliant on surrounding countries for many essential resources. There are various kinds of risks regarding climate change. One typical example would be water resources. The domestic availability of water in Singapore is quite limited. A sudden change in the climate may immediately cause a large loss in the economy not only within the region but the whole world. Recent research studies have shown that Singapore has the largest assets threatened by climate change compared with other major coastal cities in Asia [7].

This study is going to investigate several climate factors that could affect the extreme value model. These are longterm climatic change, seasonal cyclic climatic variation, and abrupt climatic changes $[8,9]$. In order to fix these ideas, our paper first will present the basic formulas and theories investigated in this study. Later, the paper will discuss the influences of various degrees of climatic uncertainties to the related output results. For simplicity, we assume the investigated problem does not include any temporal extreme climatic events (e.g. tsunami or earthquake). Our current investigation focuses only on pertinent climatic uncertainties.

\section{Extreme Changes in Singapore}

Singapore is an island on the southern tip of the Asian continental plate. It is divided by the Straits of Johor from Peninsular Malaysia to its north and by the Singapore Strait from Indonesia's Riau Islands to its south.

In Singapore, it is observed from the past that the annual mean surface temperature has risen from $26.8^{\circ} \mathrm{C}$ in 1948 to $27.6^{\circ} \mathrm{C}$ in 2011 . A general plot of this changing process is given in Fig. 1. The reason on one hand is mainly because of its fast urbanization and development, but on the other hand, the global warming effect also has exacerbated the change of the environmental structure. The human factor may also be a reason for this long-term climate change. For example, although Singapore only produces $0.39 \%$ of total Asian pollutant emissions [10], its per-capital contributor of anthropogenic emissions to the atmosphere is among the top two in Asia [11].

The seasonal effect in Singapore is also very obvious. Unlike other places in the world, Singapore is only 1.36 degrees of latitude north of the equator. Due to its high maritime exposure, the climate here is characterized by uniform temperature and pressure throughout the year. However, high humidity and abundant rainfall can be noticed in cer-

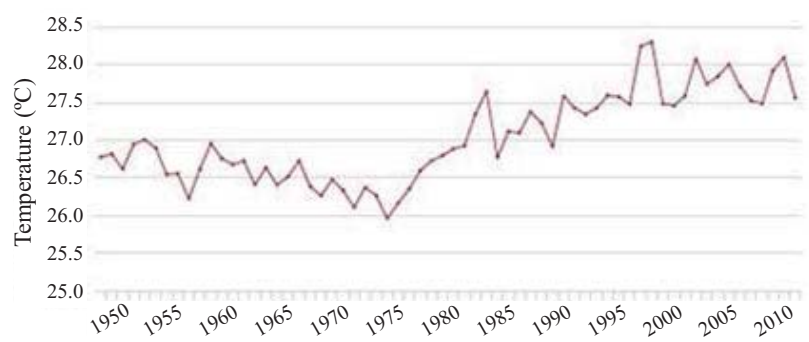

Fig. 1. Annual mean surface temperature $\left({ }^{\circ} \mathrm{C}\right)$.

Source: Meteorological Service Singapore. tain wet seasons. Fig. 2 plots the maximum monthly rainfall, temperature, humidity, and thunderstorms in Singapore for recent years. It can be seen that only the monthly extreme rainfall has a very obvious seasonal cyclic change pattern, while others are relatively less obvious. The influence of La Niña (associated with heavy rains) and tropical cyclones are very obvious, which could cause massive flooding in major rivers in Singapore. Extreme events like La Niña and tropical cyclones have brought heavy and intensive rainfall in Singapore, resulting in excessive runoff and water flows to the fragile ecosystems, which lead to massive flooding, landslides, severe erosion of river banks, and sedimentation [12]. Together with the influence of Asian monsoon, which is caused by the larger amplitude of the seasonal cycle of land temperature compared to that of nearby oceans, a prominent peak in monthly precipitation normally occurs between November and January. Lower precipitation is usually observed during the southwest monsoon period. As a result, we can see the extreme rainfall is quite sensitive to the seasonality while the remaining factors are less sensitive.

Besides the above-mentioned changes of environmental extremes during a long period, it is also expected that shortterm extremes (or irregular extremes) are quite critical for human activities. One of these short-term extreme environmental events is the tropical storm. Although tropical storms are not formed within the region of Singapore, the weather can be significantly affected. One typical case was tropical storm/typhoon Vamei on 27 December 2001, which was faced by Singapore for the first time. It formed in the South China Seamand proceeded westward and eventually landed in Singapore and te Malacca Straits. Later, it passed over Sumatra, $100 \mathrm{~km}$ south of Meulaboh, and dissipated over the Indian Ocean [13] on 1 January 2002. It brought heavy rainfall to Singapore and caused air traffic disruptions at Singapore Changi Airport. The passage of the cyclone resulted in many downed trees and caused \$3.6 million dollars in damage and five deaths. Meteorologist Richard Anthes, president of the University Corporation for Atmospheric Research in Boulder, Colorado, agreed that "this [was] quite an interesting and rare event, both in time and in place" [14].

From an economic point of view, all these extremes could lead to great impact on the whole nation. For example, the protection of flood and sea level rise demands lots of money. From 2012, PUB already released a \$750 million dollar project aimed at raising flood protection and reinforcing six major canals, like the Alexandra Canal and Rochor Canal [15]. This will also be increased in the future as growing urbanization and population is expected. The seasonal change will also trigger a shift in the nation's gross productivity. For instance, changing climates may alter the seasonal patterns of tourism (e.g. fewer people wanting to come to Singapore in the wet season) and forms of leisure activities [16]. Another thing that might be noted is the influence of seasonal effect to the death rate [17]. The change of climate structure can directly affect the functionality of land use (e.g. less land may lead to a rise in its price). A recent article reported that "economics will suffer 
a loss range between 2.9 and 15.2 percent of annual gross domestic product because of the climate change in the Pacific by 2100 " [18].

One should note that the uncertainty in the present climate model makes it difficult to predict extreme climate in the next decades. However, Singapore has already taken initiatives, such as some degree of protection. For example, according to the New York Times (29 August 2007) in "Vulnerable to rising seas, Singapore envisions a giant seawall,' Singapore has built many sea walls and breakwaters for overtopping, overturning, or breaking up to reduce its vulnerability to rising sea levels. Currently, about 70-80\% of Singapore's coastal areas have hard walls or stone embankments, which help Singapore to protect against coastal erosion. The rest are natural areas such as beaches and mangroves.

Nevertheless, the risk is complicated by the fact that no one knows for sure how much the extreme climate will be and when will it happen. Estimates of climate extreme changes can be quite different from different scenarios. For example, the estimates of sea level rise vary from as little as $60 \mathrm{~cm}$ to as much as $6 \mathrm{~m}$ [1]. Based on this concern, sometimes the uncertainties regarding risk assessment can only be roughly quantified. This is normally realized through a probabilistic approach, for example when an extreme value model is employed. However, the exact influence of climate change on an established extreme value model is still a big question. The decision of whether to use the extreme value model for climate analysis needs to be drawn from the exact uncertainty analysis [19]. This is elucidated in the following sections.

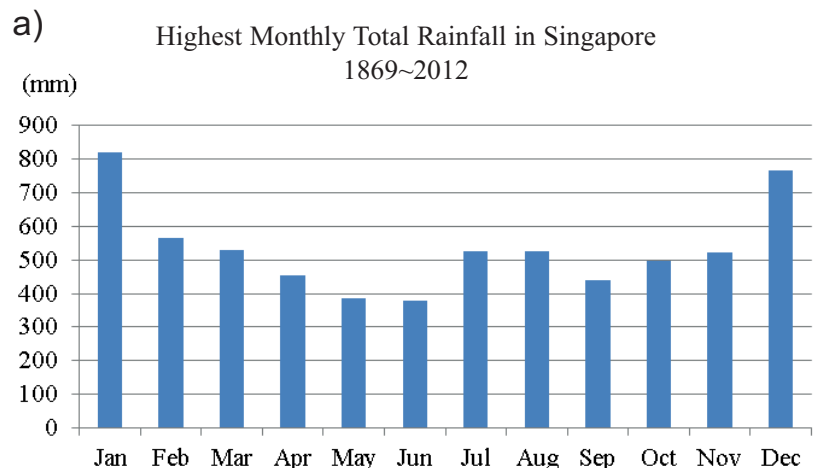

c)

(\%)

Lowest Relative Humidity in Singapore 1929-1941 and 1948-2012

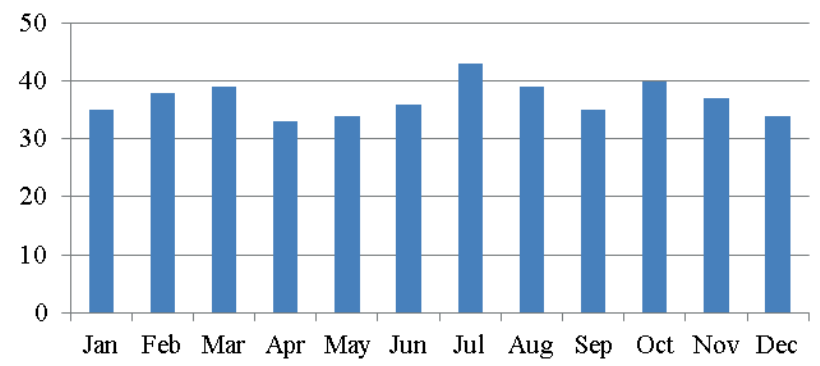

\section{Analysis of Climatic Changes in Environmental Extremes - a Statistical Approach}

This section presents a way to quantify the unpredictable climate change uncertainties in extreme value modeling. Here, the analysis adopts the traditional extreme value theory as fundamental knowledge and uses it to analyze the impact resulting from climate change [20].

\section{Classic Asymptotic Model}

We shall recall the basic classic extreme value theory developed on the modeling of the statistical behaviour of extreme values. A concerned distribution model $M_{n}$ is derived in relation to the original distribution $F$, which requires a certain group of data not exceeding the same value, $z$, is derived as [21]:

$$
\begin{aligned}
& \operatorname{Pr}\left\{M_{n} \leq \mathrm{z}\right\}=\operatorname{Pr}\left\{Y_{1} \leq z, \ldots, Y_{n} \leq z\right\}= \\
& \operatorname{Pr}\left\{Y_{1} \leq z\right\} \times \ldots \times \operatorname{Pr}\left\{Y_{n} \leq z\right\}=\{F(z)\}^{n}
\end{aligned}
$$

The estimation of the maxima involves the known information of the variable distribution $F$. Unfortunately, the distribution of the observed data is always unknown in reality. One possible way is to use standard statistical techniques to estimate $F$ from observed data, and then substitute into Eq. (1). While the data size approaches infinity, $n \rightarrow \infty$, the extremal type theorem provides the limit distribution for the behaviour of $F^{n}$. The asymptotic distribution could be obtained if there are sequences of constants $\left\{a_{n}>0\right\}$ and $\left\{b_{n}\right\}$ such that:
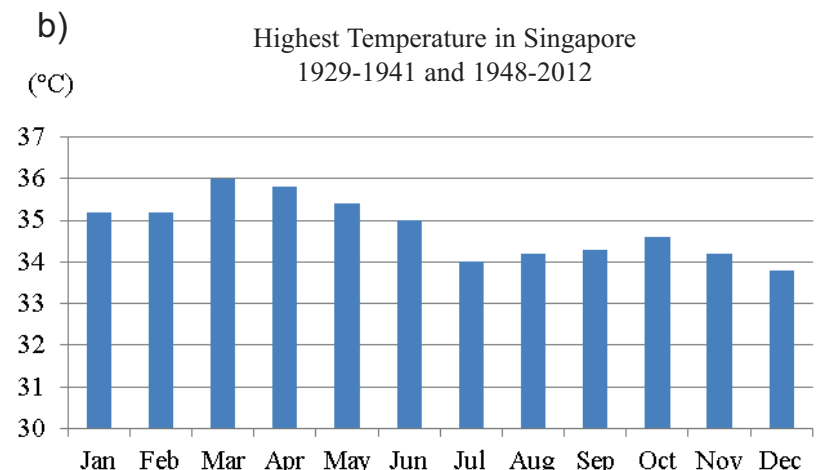

d) $\quad$ Maximum Thunderstorm days in Singapore
(days)

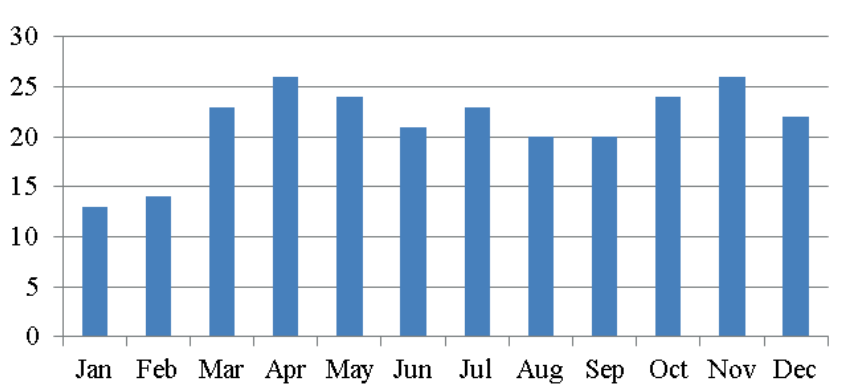

Fig. 2. Seasonal effects on extreme weather factors.

Source: Data collected from the National Environment Agency Website. 


$$
\operatorname{Pr}\left\{\left(M_{n}-b_{n}\right) / a_{n} \leq z\right\} \rightarrow G(z) \text { as } n \rightarrow \infty
$$

...where $G$ is a non-degenerate distribution function. Then function $G$ could be classified into one of the following families [22]:

$$
\begin{aligned}
& \mathrm{I}: G(z)=\exp \left\{-\exp \left[-\left(\frac{z-b}{a}\right)\right]\right\},-\infty<z<\infty \\
& \mathrm{II}: G(z)=\left\{\begin{array}{cc}
0, & \mathrm{z} \leq b, \\
\exp \left\{-\left(\frac{z-b}{a}\right)^{-\alpha}\right\} & z>b,
\end{array}\right. \\
& \mathrm{III}: G(z)=\left\{\begin{array}{cc}
\exp \left\{-\left[-\left(\frac{z-b}{a}\right)^{\alpha}\right]\right\}, & z<b, \\
1, & z \geq b,
\end{array}\right.
\end{aligned}
$$

...where each family has parameters $a$ and $b$ as scale and location, and $\alpha$ is the shape parameter. Three classes of distributions are termed to the extreme value distribution with the widely known names Gumbel, Fréchet, and Weibull families. The feature of this result is that the three types of extreme value distributions are the only possible limits for the distributions of $M_{n}$, regardless of distribution $F$ for the population. A very key issue among these three types of limit functions is the differences in tail behaviour. The density of $G$ decays exponentially for Gumbel distribution and polynomially for Fréchet distribution, corresponding to different rates of decay. The differences in families could make large differences in the estimates. Usually, the extreme value analysis is based on a more flexible model offered by the reformation of the families, a combination of Gumbel, Fréchet, and Weibull families, and the Generalized Extreme Value Distribution (GEV):

$$
G(z)= \begin{cases}\exp \left\{-\left[1+\xi\left(\frac{z-\mu}{\sigma}\right)\right]^{-1 / \xi}\right\} & \xi \neq 0 \\ \exp \left\{-\exp \left[-\left(\frac{z-\mu}{\sigma}\right)\right]\right\} & \xi=0\end{cases}
$$

Defined on the set $\{1+\xi((z-\mu) / \sigma)>0\}$, where the parameters satisfy $-\infty<\mu<\infty, \sigma>0$ and $-\infty<\xi<\infty$. Types I, II, and III classes correspond to $\xi=0, \xi>0$ or $\xi<0$, respectively.

However, the direct use of the extreme value model is a great challenge. The use of only the extremes will discard the other information provided by other data. This leads to a waste of large amounts of data. It gives the incentive to bring into use Pareto distribution or the peak over threshold (POT) approach. The theoretical basics of POT are extended from the GEV for values that exceed a certain value. The data concerned are a group of variables instead of the maxima in a block. It can be shown in a conditional probability function expressed in Eq. (6).

$$
\operatorname{Pr}\{Y>u+z \mid Y>u\}=\frac{1-F(u+z)}{1-F(u)}, \quad z>0
$$

If the parent distribution $F$ also obeys the asymptotic rule, the cumulative probability distribution function for the exceedances could be expressed as:

$$
G(z)= \begin{cases}1-\left[1+\xi\left(\frac{z-u}{\tilde{\sigma}}\right)\right]^{-1 / \xi} & \xi \neq 0 \\ 1-\exp \left[-\left(\frac{z-u}{\tilde{\sigma}}\right)\right] & \xi=0\end{cases}
$$

...where $\xi$ is the shape parameter, $\mathrm{u}$ is the threshold, and $\hat{\sigma}$ is the scale parameter, which has a relationship with other parameters in GEV at: $\hat{\sigma}=\sigma+\xi(u-\mu)$. This family of distributions is called the generalized Pareto family. It parallels the use of the GEV in the modeling of maximas. The classification of the distribution into types I, II, or III is the same as that in GEV.

\section{Peak Value and Poisson Process}

An extension of the threshold model can be obtained by a combination of Poisson process and GPD model [23]. In that case, the Poisson property of exceedances suggests the following model, which is called the Poisson-GPD model [24]:

- The number, $N$, of exceedances of level $\mathrm{u}$ in any one reference period (e.g. one year) has a Poisson distribution with mean $\lambda$.

- Conditionally on $N \geq 1$, the excess values $y_{1}, y_{2}, \ldots, y_{N}$ are identical, independently distributed from GPD.

We refer this process to an intensity function related to the GEV distribution model. The following probability distribution function that the maximum of a process, for $y>u$, is less than $z$ can be given:

$$
\begin{aligned}
& \operatorname{Pr}\left\{\max _{1 \leq i \leq N} Y_{i} \leq z\right\}=\operatorname{Pr}\{N=0\}+\sum_{n=1}^{\infty} \operatorname{Pr}\left\{N=n, Y_{1} \leq z, \cdots, Y_{n} \leq z\right\} \\
& =e^{-\lambda}+\sum_{n=1}^{\infty} \frac{\lambda^{n} e^{-\lambda}}{n !}\left\{1-\left(1+\xi \frac{z-u}{\sigma}\right)^{-1 / \xi}\right\}^{n}=\exp \left\{-\lambda\left(1+\xi \frac{z-u}{\sigma}\right)^{-1 / \xi}\right\}
\end{aligned}
$$

And the limit of Poisson process in the characterization of extremes provides:

$$
\tilde{\sigma}=\sigma+\xi(u-\mu), v=(1+\xi(u-\mu) / \sigma)^{-1 / \xi}
$$

Thus the GEV and GPD models are entirely consistent with one another. Moreover, Eq. (10) shows exactly how the Poisson-GPD model parameters vary with threshold $u$. From a mathematical point of view, this is consistent with the modern view of extremes in stationary processes. Exceedances over high threshold occur in clusters while the clusters approximately follow the Poisson process.

Based on the fundamental property of a Poisson process, for such a process $Y(t)$ within a reference period $T$, the probability of occurrence would obey the following equation: 


$$
\operatorname{Pr}\{Y(t) \leq u ; 0 \leq t \leq T\}=\exp (-\lambda T)
$$

Similarly, the upcrossing rate of a process in terms of the observed process value $Y(t)$ can be formulated as:

$$
\lambda(t)=\int_{0}^{\infty} \dot{Y}(t) f_{Y \dot{Y}}(u, \dot{Y}(t)) d \dot{Y}(t)
$$

...where $\dot{Y}(t)$ denotes the derivative of $Y(t)$ with time, and $f_{Y \dot{Y}}$ (.) represents the joint distribution of $Y(t)$ and $\dot{Y}(t)$. Hence it can be seen that the occurrence of peak values is generally relying on joint distribution, which could be either established or empirically obtained from the process.

\section{Uncertainty in Environmental Process}

The use of an extreme value model requires the data set to be stationary, independent, and identically distributed. This assumption is quite stringent. Normally, the collected data contain large uncertainties from the time-varying properties [25]. Here we will demonstrate some important issues regarding environmental process modeling. We aim to give a remarkable result in showing the influence of many commonly met climate change uncertainties to the extreme value model. A typical assertion is given here as "no parameters are constant with time." The real observed environmental processes are physical variables dependent on the natural climate. We may say, however not absolutely, that every environmental process is a varying function of time. However, climate uncertainty is elusory and can only be quantified to a certain extent.

\section{Long-Term Trend Uncertainty}

When establishing the extreme value model, a very common implicit assumption is that the model can be used for a long period. However, the real environmental process is definitely not the case. Various climatic variations can happen with physical variables (e.g. global warming). Recent works do believe that certain modifications should be made to the present model. A simple "naive" approach is to use a linear trend approach in modeling the long-term variation [26]. A linear function to characterize the scale parameter in a Pareto distribution for modeling the flood damage is proposed by Katz et al. [27]. This concept of linear varying characterization is also adopted in modeling other climate factors, such as temperature [28], precipitation [29], and wave height [30].

We adopt this assumption here in the study. The following formula is considered as a general modified extreme value model for considering a long-term trend effect:

$\operatorname{Pr}\{\max Y(t) \leq z\}=$
$\exp \left\{-\lambda(1+\alpha t)\left(1+\xi(1+\beta t) \frac{z-u(1+\gamma t)}{\sigma(1+\rho t)}\right)_{(13)}^{-1 /(\xi(1+\beta t))}\right.$

$\ldots$ where $\alpha, \beta, \gamma$, and $\rho$ are parameters representing the long-
Table 1. Investigated cases of long-term trend uncertainty in an extreme value model.

\begin{tabular}{|c|c|c|c|}
\hline \multicolumn{5}{|c|}{$z=4.5$} \\
\hline $\begin{array}{c}\text { Poisson rate } \\
\lambda\end{array}$ & $\begin{array}{c}\text { Shape } \\
\text { parameter } \xi\end{array}$ & $\begin{array}{c}\text { Location } \\
\text { parameter } u\end{array}$ & $\begin{array}{c}\text { Scale } \\
\text { parameter } \sigma\end{array}$ \\
\hline 10 & -0.5 & 1 & 2 \\
\hline \multicolumn{4}{|c|}{ Case 1} \\
\hline$\alpha=0.2$ & $\beta=0.2$ & $\gamma=0.2$ & $\rho=0.2$ \\
\hline \multicolumn{4}{|c|}{ Case 2} \\
\hline$\alpha=-0.2$ & $\beta=-0.2$ & $\gamma=-0.2$ & $\rho=-0.2$ \\
\hline \multicolumn{4}{|c|}{ Case 3} \\
\hline$\alpha=0.05$ & $\beta=0.2$ & $\gamma=0.2$ & $\rho=0.2$ \\
\hline \multicolumn{4}{|c|}{ Case 4} \\
\hline$\alpha=0.2$ & $\beta=0.05$ & $\gamma=0.2$ & $\rho=0.2$ \\
\hline \multicolumn{5}{|c|}{ Case 5} \\
\hline$\alpha=0.2$ & $\beta=0.2$ & $\gamma=0.05$ & $\rho=0.2$ \\
\hline$\alpha=0.2$ & $\beta=0.2$ & $\gamma=0.2$ & $\rho=0.05$ \\
\hline
\end{tabular}

term climate changes (e.g. linear pattern). One should note that the influence of long-term climate change may give different impacts to the parameters. These can lead to different estimates in the results. Generally, the parameters in Pareto distribution model have their own mathematical meanings:

1) the threshold generally indicates the intensity of the extreme values,

2) scale parameter describes the size of dispersion around the mean value,

3) shape parameter shows how the tail decays in the distribution function [27].

However, it is noted that the long-term changes of these parameters are rather small, which may not be easily noticed. Therefore, the time unit we used here, which is varying within $[0,1]$, may only represent the change in long-term (magnitude of one would be unimportant). For a short period of time, the sensitivity of an extreme value model will not be so sensitive. However, it is worth giving some remarkable results to reveal some of the points that may be ignored within traditional statistical treatments. Table 1 records the information of investigated cases for long-term effect.

With reasonable considerations of the values given for $\alpha$, $\beta, \gamma$, and $\rho$, the results of Eq. (14) are calculated for a specified value $z=4.5$. These are plotted in Fig. 3. As shown in the figure, a linear increasing pattern of parameters (Case 1) would lead to an increasing of non-exceedance probability, while a decreasing pattern (Case 2) shows the opposite. From the comparison of Cases 3-6, we could see that the long-term non-exceedance probability is quite sensitive to the change of shape parameter (Case 4 gives the largest 


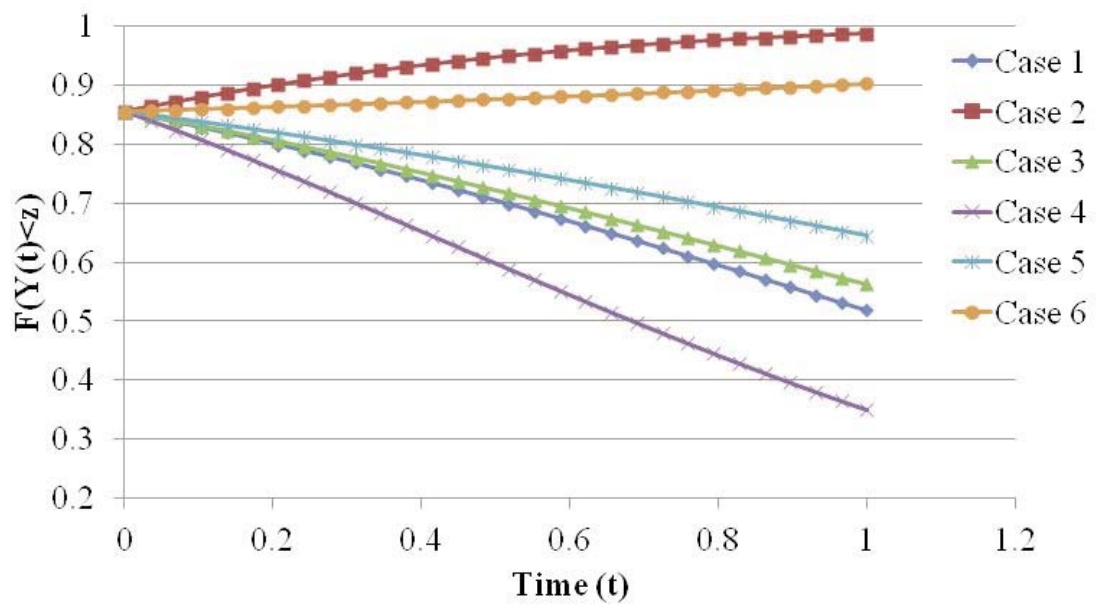

Fig. 3. Effect of long-term trend uncertainties.

value drop) and scale parameter (Case 6 gives the largest value rise). The influence from the change of the other two parameters (Cases 3 and 5) are generally small. However, we should note that an increasing rate of shape parameter would lead to large decreasing rate of non-exceedance probability. This indicates that if shape parameter is not very sensitive to the long-term changes, the established extreme value model would only have small changes and thus could still be used. However, the change of other parameters will make the non-exceedance probability larger. This implies that the extreme value model may not be robust in the long term when other parameters have changed a lot.

In the Singapore case we will expect the climate to have a long-term change. One particular example would be temperature. It is reported that the increasing rate is around $0.1 \%$ annually for the annual maximum temperature in Singapore [10]. We could see if this change is regarding an average rate for all parameters, in which case the long-term temperature change pattern will follow Case 1. However, if unequal changes are expected, further investigations may be required. For instance, if the variance of daily tempera- ture is low, which means the change of the shape parameter in the extreme value model might be small, then the nonexceeding probability for a specified extreme temperature value is expected to be lower than Case 1. From the longterm point of view, this provides people with information about whether a climate adaptation strategy is needed to consider different influences coming from different parameter changes. The detailed climate analysis could follow the statistical analysis highlighted in the above study.

\section{Seasonal Varying Pattern Uncertainty}

Another obvious statistical changing pattern that is commonly observed is that an environmental process could be seasonal changes. Most previous studies have highlighted this effect and several special statistical treatments could be found in the literature [31]. Here, an artificial seasonal uncertainty introduced by Méndez et al. [30] is introduced in this study. The seasonal uncertainty is generally modelled as a trigonometric function. This concept is now integrated into the Poisson-GPD model, which can be expressed as:

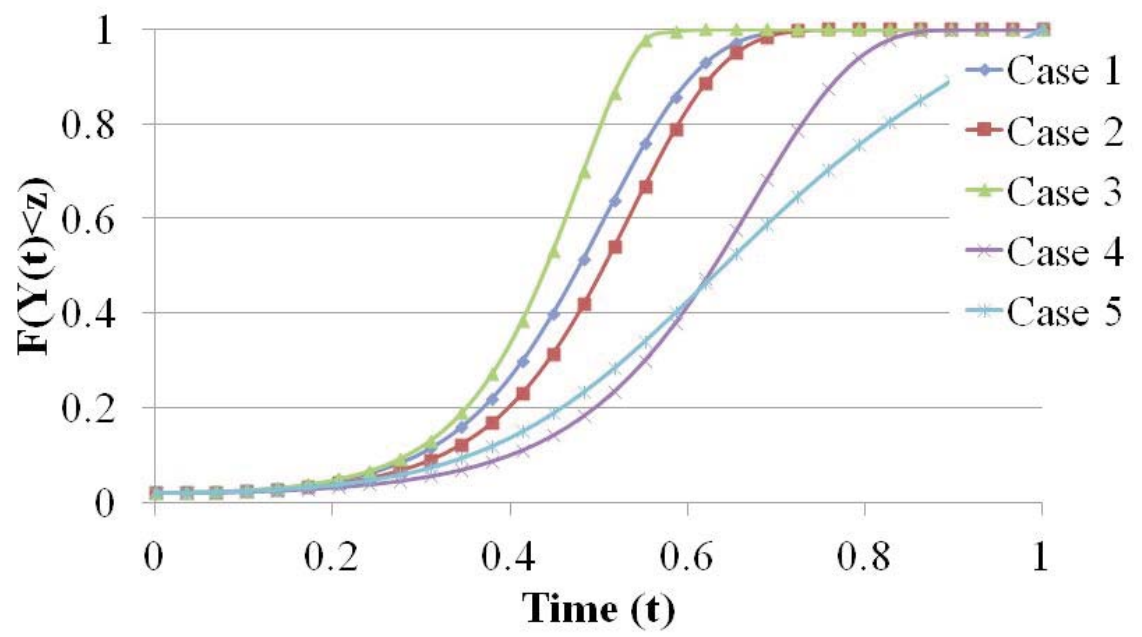

Fig. 4. Effect of the seasonal uncertainties in different parameters. 
Table 2. Investigated cases of seasonal uncertainty in the extreme value model.

\begin{tabular}{|c|c|c|c|}
\hline \multicolumn{5}{|c|}{$z=3.0$} \\
\hline $\begin{array}{c}\text { Poisson rate } \\
\lambda\end{array}$ & $\begin{array}{c}\text { Shape } \\
\text { parameter } \xi\end{array}$ & $\begin{array}{c}\text { Location } \\
\text { parameter } u\end{array}$ & $\begin{array}{c}\text { Scale } \\
\text { parameter } \sigma\end{array}$ \\
\hline 10 & -0.5 & 1 & 2 \\
\hline \multicolumn{4}{|c|}{ Case 1} \\
\hline$a=0.5$ & $b=0.5$ & $c=0.5$ & $d=0.5$ \\
\hline \multicolumn{5}{|c|}{ Case 2} \\
\hline$a=0.2$ & $b=0.5$ & $c=0.5$ & $d=0.5$ \\
\hline \multicolumn{5}{|c|}{ Case 4} \\
\hline$a=0.5$ & $b=0.2$ & $c=0.5$ & $d=0.5$ \\
\hline \multicolumn{5}{|c|}{ Case 5} \\
\hline$a=0.5$ & $b=0.5$ & $c=0.2$ & $d=0.5$ \\
\hline \multicolumn{5}{|c|}{$b=0.5$} & $c=0.5$ & $d=0.2$ \\
\hline$a=0.5$ &
\end{tabular}

$\operatorname{Pr}\{\max Y(t) \leq z\}=$
$\exp \left\{-\lambda \cos (a \pi t)\left(1+\xi \cos (b \pi t) \frac{z-u \cos (c \pi t)}{\sigma \cos (d \pi t)}\right)_{(14)}^{-1 /(\xi \cos (b \pi t))}\right\}$

....where $a, b, c$, and d represent the influences of the seasonal effect to parameters $\lambda, \xi, u$, and $\sigma$, respectively. A fact is that the values of $a, b, c$, and d are very close according to prior researcher's works, which were estimated based on Fourier series [31]. But the varying of the exceedance probability over value $z=3.0$ along the process is quite sensitive to these values. Here, we investigate the following cases (Table 2).

The effect of these uncertainties can be observed at the changes of exceedance probability of process $Y(t)$ (Fig. 4). The graph generally demonstrates the influence of the uncertainties of different parameters to the overall extreme value model for the process. An amazing finding is that when the scale parameter is less sensitive to the seasonal varying uncertainty (Case 5), the non-exceedance probability $F(Y(t)<z)$ of the process tends to be low. This may indicate the importance of the scale parameter when we establish an extreme value model for the observed environmental data. Another issue would be the sensitivity of the nonexceedance probability to time. As seen in Fig. 4, the decrease of shape parameter would lead to an increase in the change rate of non-exceedance probability (Case 3 ). This generally implies that a sudden change in the seasonal effect for shape parameter may lead to a sudden variation in the extreme value model. Therefore, we should pay more attention to the seasonal cyclic effect in the shape parameter.

The same problem is analyzed again while the Poisson rate $\lambda$ is now changed to 50 (Fig. 5). As expected, the nonexceedance probability now becomes smaller compared to the former case. The sensitivity of the exceedance probability in terms of the seasonal changes becomes quite large as the plot of $F(Y(t)<z)$ is much steeper compared with the previous study. However, the increasing of $\lambda$ does not affect the orders of the importance of the uncertainties in the parameters. The amount of changes in exceedance probability is still quite critical and very obvious through time. The establishment of a statistical model based on seasonality is an essential procedure.

The lessons learned from this study is that we should recognize the seasonal variations in the modelling of extremes. In Singapore, the maximum daily rainfall shows the most obvious seasonal varying pattern (Fig. 2). The difference between the dry and monsoon seasons is nearly $50 \%$. The frequency of this change in Singapore is usually observed once a year. The collected rainfall data shows that the maximum rainfall varies significantly among the years [13]. This means the seasonal variations in scale parameter is large (the value of $\sigma$ ). From this study, we would see this phenomenon will give a lower non-exceeding probability compared to the usual case (Case 1), which assumes all the parameters undergo an equal cyclic seasonal change process. Therefore, the value of rainfall extremes may be underestimated if seasonal influence is ignored. This might create some errors in urban design (e.g. the design of the reservoir) and thus lead to unexpected economic loss.

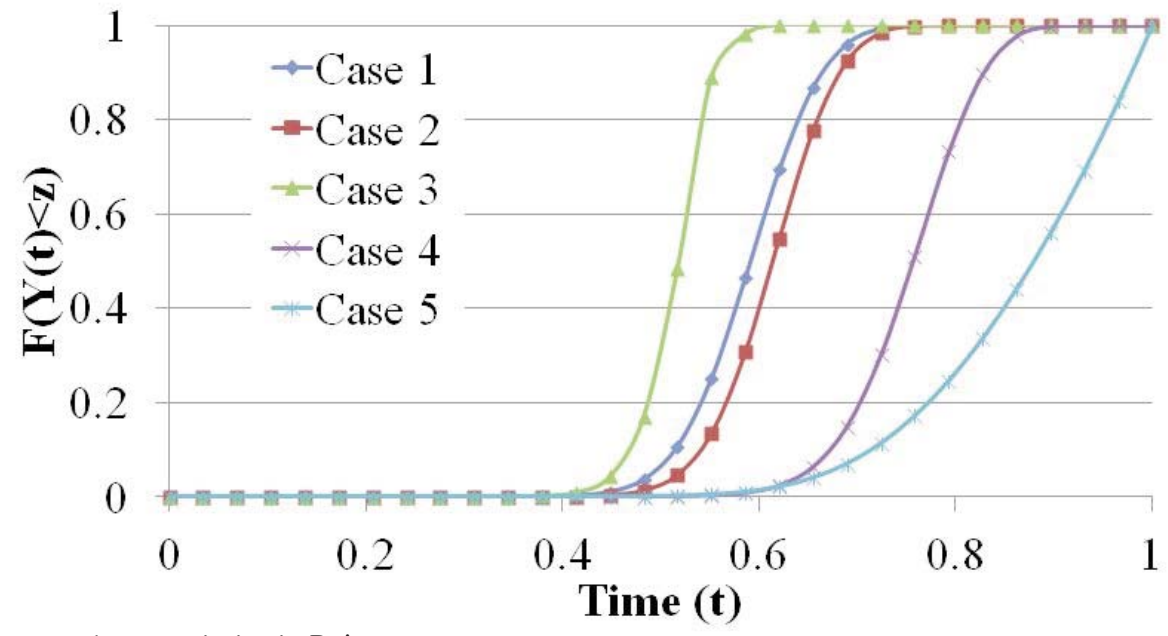

Fig. 5. Effect of seasonal uncertainties in Poisson rate. 
Table 3. Investigated cases of noise uncertainty in the extreme value model.

\begin{tabular}{|c|c|c|c|}
\hline \multicolumn{5}{|c|}{$z=4.0$} \\
\hline $\begin{array}{c}\text { Poisson rate } \\
\lambda\end{array}$ & $\begin{array}{c}\text { Shape } \\
\text { parameter } \xi\end{array}$ & $\begin{array}{c}\text { Location } \\
\text { parameter } u\end{array}$ & $\begin{array}{c}\text { Scale } \\
\text { parameter } \sigma\end{array}$ \\
\hline 10 & -0.5 & 1 & 2 \\
\hline \multicolumn{4}{|c|}{ Case 1} \\
\hline$\tau=0.02$ & $\theta=0.02$ & $v=0.02$ & $\delta=0.02$ \\
\hline \multicolumn{4}{|c|}{ Case 2} \\
\hline$\tau=0.10$ & $\theta=0.02$ & $v=0.02$ & $\delta=0.02$ \\
\hline \multicolumn{4}{|c|}{ Case 3} \\
\hline$\tau=0.02$ & $\theta=0.10$ & $v=0.02$ & $\delta=0.02$ \\
\hline \multicolumn{3}{|c|}{ Case 4} \\
\hline$\tau=0.02$ & $\theta=0.02$ & $v=0.10$ & $\delta=0.02$ \\
\hline \multicolumn{3}{|c|}{ Case 5} \\
\hline \multirow{4}{|c|}{$\theta=0.02$} & $\theta=0.02$ & $v=0.02$ & $\delta=0.10$ \\
\hline
\end{tabular}

\section{Common Instantaneous Climatic Uncertainty}

Obviously, the most critical climatic uncertainty would be induced by a temporary event, for example storms or hurricanes. Unfortunately, natural events are usually unpredictable and thus are quite difficult to be assessed in a statistical model. However, instead of modeling the changing pattern, we aim to give quantitatively answers to this particular problem. The case considered in this study is adopting a noisy time series to characterize the unexpected events. Here, we set an equal degree of uncertainty (e.g. noise) to each of the parameters. For the sake of nonbiased purpose, the Gaussian noise is applied. The typical case study considered would be expressed in the following:
Table 4. Results of non-exceedance probability for noise uncertainty in the extreme value model.

\begin{tabular}{|c|c|c|c|c|c|}
\hline & Case 1 & Case 2 & Case 3 & Case 4 & Case 5 \\
\hline $\begin{array}{c}\text { Average } \\
\text { non-exceedance } \\
\text { probability }\end{array}$ & 0.5357 & 0.5410 & 0.5521 & 0.5331 & 0.5230 \\
\hline $\begin{array}{c}\text { Maximum } \\
\text { non-exceedance } \\
\text { probability }\end{array}$ & 0.6632 & 0.6482 & 0.8557 & 0.7926 & 1 \\
\hline
\end{tabular}

$$
\begin{gathered}
\operatorname{Pr}\{\max Y(t) \leq z\}= \\
\exp \left\{-\lambda\left(1+N\left(0, \tau(t)^{2}\right)\right)\left(1+\xi N\left(0, \theta(t)^{2}\right) \frac{z-u\left(1+N\left(0, v(t)^{2}\right)\right)}{\sigma\left(1+N\left(0, \delta(t)^{2}\right)\right)}\right)^{-1 /\left(\xi\left(1+N\left(0, \theta(t)^{2}\right)\right)\right)}\right.
\end{gathered}
$$

...where $\tau, \theta, v$, and $\delta$ are the associated noises with the extreme value model parameters. The noises in terms of variance would indicate an environmental condition. For example, it is usually believed that an environmental hazard would induce large noises in the statistical parameters. To consider this effect, the following criteria will be used to analyze the importance of uncertainty quantities in such a stochastic process. A criteria defining a value $H(t)$ for the process $Y(t)$ such that:

$$
\begin{gathered}
H(t)=1, \quad \text { for } Y(t) \leq u \\
=0, \quad \text { else if not }
\end{gathered}
$$

Obviously, the estimates of the exceedance probability following Eq. (15) are as follows:

$$
E(H(t))=\frac{1}{T} \int_{0}^{T} H(t) d t=\operatorname{Pr}\{Y(t) \leq u ; 0 \leq t \leq T\}
$$

...while the assumption of ergodicity is exploited. In order to emphasize our problem on the parameter uncertainty, we assume the noises to be stationary. That is, the variance

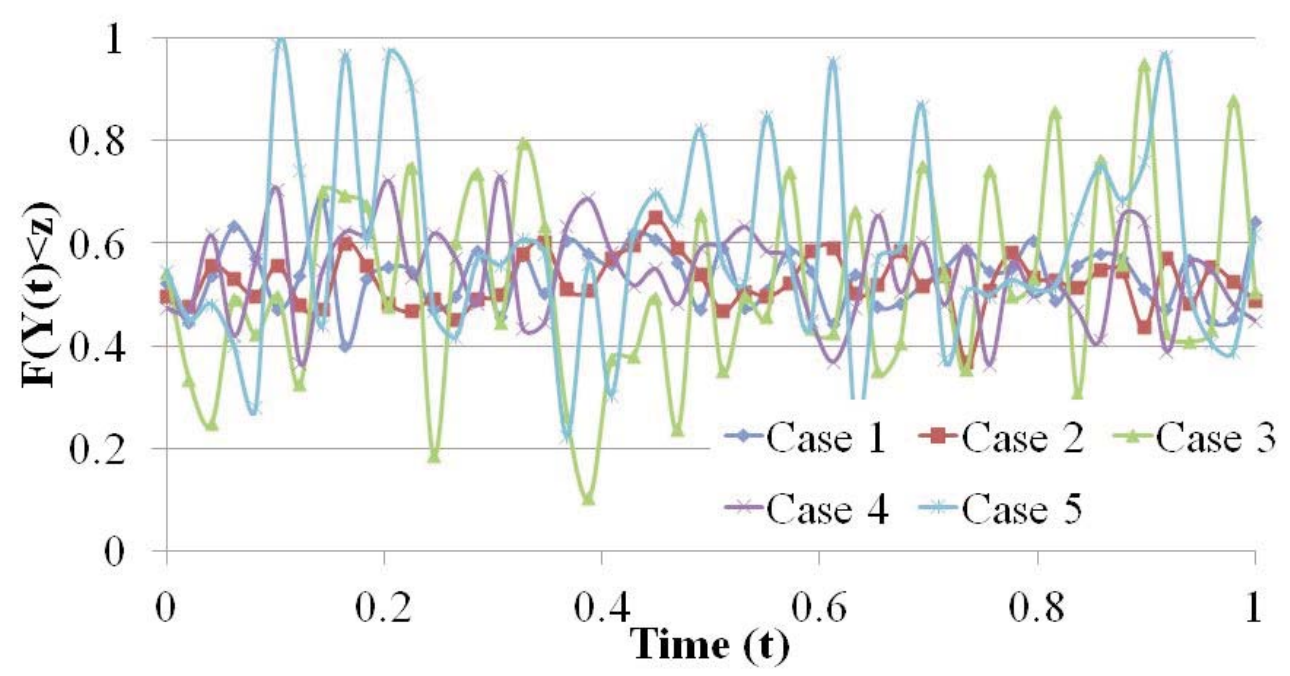

Fig. 6. Simulation of extreme value model for the effect of noises. 
remains constant in the analyzed stochastic process. In order to have an accurate estimation of exceedance probability, the function value of Eq. (15) for a time step at 0.01 is calculated. For general comparing purposes, several cases of different uncertainty intensities are considered (Table 3).

The simulated processes (time step $=0.01$ ) are shown in Fig. 6. The results in terms of average and maximum nonexceedance probability are also given in Table 4. It is observed that the average non-exceedance probability is nearly the same in all cases. This means that the noise effect is generally very small for the mean value of the extreme value model. But the variations in the non-exceedance probability are quite different among these cases. We could see that the scale parameter in this case gives the largest impact to the variations, which can be shown in the graph (large fluctuations) and table (largest maximum nonexceedance probability). The noise effect of other parameters also can affect the extreme value model in the maximum non-exceedance probability. This reveals a very common mistake that we usually made in the extreme value modeling. The collected data having the same mean value or variance may not follow the same extreme value model as noise conditions may be different. A change in noise conditions would surely result in significant uncertainty in the estimates. Thus, we would not suggest the use of a single extreme value model to characterize a stochastic process with unknown information about noise intensity.

To the author's knowledge, in reality the intensity of these noises have different quantities for the extreme value model parameters (large differences in the values of $\tau, \theta, v$, and $\delta$ ). The shape parameter of an extreme environmental model is usually observed to have the most sensitive terms (e.g. large $\theta$ ) to a harsh environmental condition. This is thus a particularly important point that we should pay attention to. Some specific sites, for example an ocean site, may have a different noise uncertainty due to their natural characteristics. Though the situation is usually not easy to be handled, the importance in the estimates should draw our attention. Therefore, we put this noisy problem to the most noteworthy place for climatic uncertainty considerations. For the Singapore case, the short-term climatic changes are quite common. Typical examples could be wind speed and rainfall intensity. Fortunately, the magnitude of these unexpected short-term events are not severe. However, one might need to notice that certain natural accidents might lead to instantaneous changes in the climate system of Singapore. The well known Southeast Asian haze, which is caused by large-scale burning in many parts of Sumatra and Borneo, is an example. This immediate change can significantly affect the nation's economy $[32,33]$. Most importantly, we need to know which parameters of the extreme value model have been affected most.

Generally, the above-investigated uncertainties are only represented by some established artificial functions. We would not want to restrict our investigation only within the existing forms of uncertainties. The climate-changeinduced uncertainty is rather broad, which may consist in both long- and short-term uncertainties. It is hard to imag- ine how much uncertainty may exist in a conventional extreme value model. The characterization of the environment-induced uncertainty must rely on a large amount of data. The separation of different groups of uncertainty is critical for establishing a robust extreme value model. The present work serves only as a preliminary theoretical foundation for any further climatic uncertainty problems.

\section{Conclusion}

This paper briefly discussed the changes of environmental extremes in Singapore. Based on historical records, changes in long- and short-term climates are identified. The risks associated with the climate change are discussed in several cases considering different long- and short-term scenarios. It has been shown that sea level rise can have the greatest influence on a nation's economy and human activities. This paper also provided a study on the influence of climate uncertainties to the extreme value model. The study investigated the influence of uncertainties for seasonal cyclic varying, long-term trends, and short-term changes. It was shown that the extreme value model is very sensitive to the types of uncertainty existing in the time series. The present work provides the information for people to know the climate variability within an extreme value model.

\section{References}

1. IPCC. Special report on managing the risks of extreme events and disasters to advance climate change adaption, Cambridge University Press, 2012.

2. COUMOU D., RAHMSTORF S. A decade of weather extremes. Nature Climate Change 2, 491, 2012.

3. FOLEY J.A. Tipping points in the tundra. Science 310, 5748, 2005.

4. MIN S.K., ZHANG X., ZWIERS F.W., HEGERL G.C. Human contribution to more-intense precipitation extremes. Nature 470, 7334, 2011.

5. CALZADILlA A., REHDANZ K., BETTS R. Climate change impacts on global agriculture. Climatic Change 120, $1,2013$.

6. BECKER A., INOUE S., FISCHER M., SCHWEGLER B. Climate change impacts on international seaports: knowledge, perceptions, and planning efforts among port administrators. Climatic Change 110, 1, 2012

7. WORLD WILDLIFE FUND (WWF), Mega-Stress for Mega-Cities: a Climate Vulnerability Ranking of Major Coastal Cities in Asia. WWF: Switzerland, 2009.

8. ZHANG Y., CAO Y.Y. Fuzzy quantification of uncertainties in extreme wave height modeling. Acta Oceanologica Sinica 34, 3, 2015.

9. ZHANG Y., LAM J.S.L. Non-conventional modeling of extreme significant wave height through random sets. Acta Oceanologica Sinica 33, 7, 2014.

10. OHARA T., AKIMOTO H., KUROKAWA J., HORII N., YAMAJI K., YAN X., HAYASAKA T.An Asian emission inventory of anthropogenic emission sources for the period 1980-2020. Atmospheric Chemistry and Physics 7, 4417, 2007. 
11. LAM J.S.L., CHEN D., CHENG F., WONG K. Assessment of the competitiveness of ports as bunkering hubs: empirical studies on Singapore and Shanghai. Transport. J. 50, 2, 2011.

12. ASIAN DEVELOPMENT BANK (ADB), Report on: The Economics of Climate Change in Southeast Asia: A Regional Review, Asian Development Bank: Manila, 2009.

13. MONECKE K., FINGER W., KLARER D., KONGKO W., MCADOO B.G., MOORE A.L., SUDRAJAT S.U. A 1,000year sediment record of tsunami recurrence in northern Sumatra. Nature 455, 1232, 2008.

14. CHANG C.P., LIU C.H., KUO H.C. Typhoon Vamei: an equitorial tropical cyclone formation. Available online: http://www.weather.nps.navy.mil/cpchang/papers/vamei/va mei.htm [accessed 15 May 2013].

15. BUSINESS REVIEW, Singapore throws $\$ 750$ million at flood and drainage problem, Tim Charlton, 2012.

16. TOL R.S.J. Low probability, high impact: the implications of a break-up of China for carbon dioxide emissions. Climatic Change 117, 4, 2013.

17. PARKER G., GAO F., MACHIN D. Seasonality of suicide in Singapore: Data from the equator. Psychol. Med. 31, 3, 2001.

18. AGENCE FRANCE-PRESSE (AFP), Climate change will cause 'serious economic losses' in Pacific. Available online: http://au.news.yahoo.com/world/a/20025292/climatechange-will-cause-serious-economic-losses-in-pacific/ [accessed 15 May 2013].

19. BEER M., ZHANG Y., QUEK S.T., PHOON K.K. Reliability analysis with scarce information: Comparing alternative approaches in a geotechnical engineering context. Struct. Saf. 41, 1, 2013.

20. COOLEY D. Extreme value analysis and the study of climate change. Climatic Change 97, 77, 2009.

21. GUMBEL E.J. Statistics of extremes, New York, 1958.
22. COLES S.G., An introduction to statistical modeling of extreme values, New York, 2001.

23. DAVISON A.C., SMITH R.L. Models for exceedances over high thresholds (with Discussion). Journal of Royal Statistics Society B52, 393, 1990.

24. LEADBETTER M.R., LINDGREN G., ROOTZÉN H., Extremes and Related Properties of Random Sequences and Series, New York, 1983.

25. VISSER H., PETERSEN A.C. Inferences on weather extremes and weather-related disasters. Climate of the Past 8, 265, 2012.

26. RUGGIERO P., KOMAR P.D., ALLAN J.C. Increasing wave heights and extreme value projections: The wave climate of the US Pacific Northwest. Coast. Eng. 57, 5, 2010.

27. KARTZ R.W. Statistics of extremes in hydrology. Adv. Water Resour. 25, 1287, 2002

28. FOWLER H.J., COOLEY D., SAIN S.R., THURSTON M. Detecting change in UK extreme precipitation using results from the climateprediction.net BBC climate change experiments. Extremes 13, 241, 2010.

29. TRÖMEL S., SCHÖNWIESE C.D. Robust trend estimation of observed German precipitation. Theor. Appl. Climatol. 93, $1,2008$.

30. MÉNDEZ F.J., MENÉNDEZ M., LUCEÑO A., LOSADA I.J. Estimation of the long-term variability of extreme significant wave height using a time-dependent Peak Over Threshold (POT) model. J. Geophys. Res. 111, C7, 2006.

31. JONATHAN P., EWANS K. Modeling the Seasonality of Extreme Waves in the Gulf of Mexico. J. Offshore Mech. Arct. 133, 2, 2011.

32. LAM J.S.L., NOTTEBOOM T. The greening of ports: a comparison of port management tools used by leading ports in Asia and Europe. Transport Rev. 34, 2, 2014.

33. YAP W.Y., LAM J.S.L. 80 million-twenty-foot-equivalentunit container port? Sustainability issues in port and coastal development. Ocean Coast. Manage. 71, 13, 2013. 